\title{
Training in ENT; a comprehensive review of existing evidence*
}

\author{
Pavol Šurda', Aleksandra Barac², Puya Mobaraki Deghani³, Thomas \\ Jacques ${ }^{4}$, Cristobal Langdon', João Pimentel ${ }^{6}$, Alexander G. Mathioudakis, http://doi.org/10.4193/RHINOL/18.027 \\ Peter Valentin Tomazic ${ }^{8}$ \\ 1 Department of Otorhinolaryngology, Guy's and St Thomas'University Hospital, London, United Kingdom \\ *Received for publication: \\ June 24, 2018 \\ ${ }^{2}$ Clinical Centre of Serbia, Faculty of Medicine, University of Belgrade, Serbia \\ Accepted: July 25, 2018 \\ ${ }^{3}$ Section of Otorhinolaryngology - Head \& Neck, Gubbio-Gualdo Tadino Hospital, USL Umbria, Italy \\ Published: July 27, 2018 \\ ${ }^{3}$ Association 'Naso Sano' Onlus, Umbria Regional Registry of Volunteer Activities Corciano, Italy \\ ${ }^{4}$ Department of Otorhinolaryngology, Imperial College Healthcare, London, United Kingdom \\ ${ }^{5}$ Rhinology Unit and Smell Clinic, Otorhinolaryngology Department, Hospital Clinic, Universitat de Barcelona, Spain \\ ${ }^{6}$ Department of Otorhinolaryngology, University Hospital of Lisbon, Portugal \\ 7 Division of Infection, Immunity and Respiratory Medicine, The University of Manchester, Manchester, United Kingdom \\ ${ }^{8}$ Deptartment of General ORL, Head and Neck Surgery, Medical University of Graz, Graz, Austria
}

Rhinology Online, Vol 1: 77-84, 2018

\begin{abstract}
Despite an expansion of fellowship opportunities over the last three decades, there is still incomplete regulation and standardisation of fellowship training. The aim of this comprehensive review was to examine existing evidence about the ear, nose and throat (ENT) training, especially focused on surgical and non-surgical aspects of the training. It is challenging to critically evaluate and compare training programmes across nations for several reasons. Studies on the subject rely entirely on trainee self-reports, without any objective comparators between groups. No evidence exists that directly compares the theoretical or practical attainment of trainees between nations. More fundamentally, trainee exposure to, and competence in, elective surgical procedures, is not the sole measure of a training programme, nor can it be viewed in isolation from the health system's expectations of a newlyqualified specialist, which may vary. During recent years, the Internet and e-learning methods were implemented into the training curriculum. Also, there is an increasing number of platforms that can host the ENT learning content free of charge. Novel educational tools are powerful alternative to standard teaching techniques within otorhinolaryngology education for both residents and medical students. Overall evidence for virtual reality (VR) simulators could be implemented as adjunct in training programs but cannot replace conventional methods. This is mainly due to the fact that actual surgical outcomes after VR training have not been studied so far, but may be the content of future larger scale studies.
\end{abstract}

The otolaryngologists' non-surgical training needs to extend beyond the limits of ENT as skills and experience in areas of ENT, respiratory medicine, allergology, infectious diseases, radiology and oncology are required in the diagnosis and management of ENT diseases.

Key words: training, fellowships, rhinology, virtual reality, education

\section{Introduction}

The practice of otolaryngology has changed over the years, and has undergone the formation of subspecialties due to advances in medical care, research and technology. The educational enterprise that supports growth and development has also changed along with the evolving clinical practice ${ }^{(1)}$. In rhinology, since the 1960s when Hopkins patented his first endoscope, surgery of the nose, the sinuses and the skull base has evolved with enormous speed (2). Surgeons now operate within a complex sinonasal anatomy in close relation to vital structures, such as the brain and orbit. Trainees now require complex skills, reflected by the relatively new phenomenon of fellowship training. Despite an expansion of fellowship opportunities over the last three decades, there is still incomplete regulation and standardisation 
of fellowship training ${ }^{(3)}$. These changes need to be understood in order to help shape the future in a way that will ultimately benefit both patients and the specialty itself.

The aim of this comprehensive review was to examine existing evidence about ENT training. We have focused on two main categories: surgical and non-surgical aspects of training.

\section{Non-surgical aspects of training}

Differences in ENT training programmes across Europe The principles on which surgical residency training is based were first conceived by the German surgeon Bernhardt von Langenbeck, during his tenure at the Charité University Hospital in Berlin. He formulated a system whereby junior surgeons lived at the hospital, and were given progressive exposure to surgery and responsibility for patients over time. These principles were then propagated by Halsted and Osler, co-founders of the Johns Hopkins Hospital, and still form the basis of surgical training worldwide.

Despite this unified beginning, the format and standards of surgical training vary considerably between countries and regions. In otorhinolaryngology, head and neck surgery (ORL-HNS), no universal standards exist that define comprehensive training in the specialty. The Union Européenne des Médecins Spécialistes (UEMS) European Board Examination in ORL-HNS was created in 2008, with the intention of establishing a supranational accreditation for ENT surgeons, and to respond to the challenges presented by free movement of labour. UEMS has worked over the past decade to exert pressure on national training schemes to harmonise training programmes in terms of content and length (a minimum of five years is stipulated, but not currently adhered to in all nations).

The UEMS ORL logbook (most recently revised in 2018) forms a key part of the effort towards pan-European standardisation. It states broader principles of effective higher surgical training (graded exposure, competency-based assessment), and details the breadth of exposure that should be expected of European training programmes. In particular, the logbook sets out a comprehensive list of procedural and surgical skills, alongside the level of familiarity expected of trainees at the time of programme completion.

The European Board Examination (EBEORL) is explicitly not intended to represent a standardised exit exam across Europe. Uptake of the examination varies across EU member states, but is increasing since its inception. However, for several smaller EU countries, it has been adopted as a fellowship/exit exam, with the obvious benefits being decreased local administrative costs, and increased credibility of graduating trainees across the con- tinent. In addition, a large proportion of candidates sitting the exam originate from outside the EU which is changing as several European countries have adopted the EBEORL as their exit exam for trainees ${ }^{(4)}$.

The Union Européenne des Médecins Spécialistes (UEMS) European Board Examination in ORL-HNS was created in 2008, with the intention of establishing a supranational accreditation for ENT surgeons, and addressing the challenges presented by free movement of labour. The exam, and its accompanying standardised logbook have limited uptake across the continent, and is explicitly not intended to represent a standardised exit exam. Indeed, a large proportion of candidates sitting the exam originate from outside the $\mathrm{EU}{ }^{(4)}$.

Despite these efforts at standardisation across Europe, trainee reports indicate some similarities, but significant variability in training culture. A recent series of studies has examined the findings of surveys of residents across the training programmes of six European nations ${ }^{(5)}$. Training programmes vary in length from four to six years. Entry to residency is determined largely by national or university examination scores. Successful exit from training often requires the completion of an exam (which varies in format), and in some nations the completion of a doctoral thesis. In some nations (e.g. Italy), residents spend their training period in one or two departments, which may be district or university hospitals, whereas in others (e.g. France) trainees rotate periodically between a larger pool of mostly university-affiliated institutions. Residents in some countries (e.g. Germany) reported difficulty in obtaining operative experience, which was felt to be allocated unfairly based on the approval of senior doctors. A 2015 survey-based study cites this one reason for a disparity in trainees' reports of their surgical competence between Germany and France ${ }^{(6)}$. Nevertheless, trainee quality-of-life and working conditions were reportedly highest in Germany compared to Spain and France, where low pay in inflexible working conditions was cited by residents ${ }^{(7)}$.

In the past 15 years, limitations on the working hours of surgical residents have come into force in both the USA and Europe. In 2003, the USA Accreditation Council of Graduate Medical Education (ACGME) limited residents' weekly working hours to 80 , with restrictions on rest periods and on-call frequency. A 2009 study of US otolaryngology residents showed no significant change in examination scores or hours spent as main surgeon, following implementation of the ACGME directive ${ }^{(7)}$. From 2009, the European Working Time Directive (EWTD) has restricted surgical residents' working hours more significantly, to an average of 48 hours per week. The effect of these restrictions has been to decrease the operative exposure of UK ENT residents by up to $38 \%{ }^{(8)}$. This is due to a decrease in overall hours, but also in the percentage of time spent on educational sessions (which occur 
predominantly during office hours).

It is challenging to critically evaluate and compare training programmes across nations for several reasons. Studies on the subject rely entirely on trainee self-reports, without any objective comparators between groups. No evidence exists that directly compares the theoretical or practical attainment of trainees between nations. More fundamentally, trainee exposure to, and competence in, elective surgical procedures, is not the sole measure of a training programme, nor can it be viewed in isolation from the health system's expectations of a newly-qualified specialist, which may vary.

With a trend toward subspecialisation in ENT, fellowships became a popular way to intensify training. They are taken up in addition to specialty training and can be done at any time, but most benefit will be obtained when a trainee is close to the completion of training. Most fellowships last for a year, although some can be for a shorter time. ENT residents may be motivated to pursue a fellowship for two main reasons: to gain advanced operative experience in their chosen subspecialty, and/or to compensate for insufficient clinical or operative exposure in their training programme. Subspecialist fellowships in rhinology and anterior skull base surgery have expanded significantly in recent years, with generally positive trainee feedback ${ }^{(10)}$. Rhinology-based fellowships in skull base surgery allow trainees to achieve high levels of confidence in endoscopic anterior skull base procedures. Fellows then continue to perform such procedures in their independent practices ${ }^{(11)}$. The Confederation of European Otorhinolaryngology and Head and Neck Surgery (CEORLHNS) has directly financed a number of year-long subspecialty fellowships across European centres of excellence since 2015. These consist of two consecutive attachments of six months each at centres of excellence in particular field. Funding has come from the CEORL which derives its income from its biennial congresses and is dependent upon the financial success of such congresses.

At the moment, there are still considerable differences between national training programmes, but this does not necessarily imply that the patients in that country are being ill-served. Important steps forward are initiatives of supranational accreditation for ENT surgeons. Further work is therefore required in defining the essential and universal aims of training in ORL-HNS, in the sense of a universal curriculum, a minimum level of operative exposure, and a set of minimum competencies that prepare an otolaryngologist for safe independent practice. However, it is imperative that in managing their residency programmes surgical education leaders are mindful of the experience of local trainees, as well as the strengths and weaknesses of other national training schemes.
Multidisciplinary approach to composition of training curriculum; a missing link

The human body, being the most complicated and integrated biological system, is characterised by significant interactions and cross-talk among individual organs. The boundaries of the ear, nose and throat with other organs, such as the respiratory system, are thin, as they are affected by multi-organ and systemic diseases. In addition, skills and experience in areas of other medical specialties, such as radiology, oncology and infectious diseases, are required in the diagnosis and management of ENT diseases. For this reason, several diseases require a multidisciplinary approach, but also, otolaryngologists' training needs to extend beyond the limits of the ear, nose and throat. These topics should be accounted for in the development of training curriculums in otolaryngology.

Upper and lower airways represent a continuum; several disease entities affect both, and their management needs to be holistic and coordinated. Firstly, allergic rhinitis and chronic rhinosinusitis are interlinked with airway diseases and specifically asthma ${ }^{(11-13)}$. Patients with atopy often present to otolaryngologists, whose role in early recognition, prevention, as well as holistic management of asthma is integral ${ }^{(15)}$. However, the link between respiratory and ENT specialists extends beyond allergy. Upper airway pathology is often the cause of obstructive sleep apnea ${ }^{(14-19)}$. More importantly, vocal cord dysfunction, a significantly under-recognised and misdiagnosed cause of respiratory morbidity, can be easily identified by the experienced and sensitised otolaryngologist during laryngoscopy ${ }^{(20)}$. Due to this overlap, it has been suggested that otolaryngologists in training should spend time in respiratory or allergy clinics or departments in order to gain relevant experience. In addition, attendance of severe asthma, sleep and larger airway multidisciplinary team meetings is integral.

Radiology and oncology are core skills for an otolaryngologist. Medical imaging facilitates the diagnosis of most ENT diseases and guides surgical treatment. Cancer represents a frequent and demanding presentation for all specialties, and ENT clinicians have a leading role in the diagnosis as well as management of patients with ear, nose or throat malignancies. This should be reflected in the training curriculums. Continuous high-quality training is required. Radiology and oncology multidisciplinary meetings provide excellent educational opportunities, and teaching from all participating specialists needs to be a prioritised aim of any such meeting.

\section{The role of e-learning in residency training}

During past decades, the internet has gradually evolved into a worldwide network, allowing access to vast amounts of information and providing various services ${ }^{(21)}$. Web-learning in 
medical education is becoming increasingly popular as it offers advantages over traditional teaching methods such as flexible scheduling, reduced costs and individualised instructions. In surgical specialties, e-learning encompasses the use of virtual patient cases, digital modelling, and online tutorials, as well as standardised video and imaging ${ }^{(22)}$.

There are several papers reporting the effectiveness of e-learning methods which were implemented into a training curriculum ${ }^{(23)}$. Mendez et al. found that the use of educational video modules was associated with fewer surgical errors and less attending take over events ${ }^{(26)}$. Beyea et al. found that residents whose learning took place primarily through web-based video modules were better able to perform the particle repositioning manoeuvre (PRM) than those who learned the PRM through classroom instruction ${ }^{(25)}$.

Currently, there is an increasing number of platforms that can host learning content free of charge ${ }^{(28)}$. Hughes et al. provide a brief synopsis of user-generated, otolaryngology-specific educational channels on the popular website YouTube (Google, Mountain View, CA) ${ }^{(27)}$. A recent review of mobile app stores found 75 mobile apps (as of September 2014) related to resident, student, and patient education within otolaryngology, head and neck surgery. Among these, apps like "ENT for Students," "ENT Surgery Handbook," and "LearnENT" were highly rated among users and available on multiple platforms ${ }^{(30)}$. The content of these resources in most cases varies and was not evaluated for educational value or efficacy ${ }^{(29)}$.

The efficacy of these novel educational tools was examined in a comprehensive systematic review which shows e-learning to be a powerful alternative to standard teaching techniques within otolaryngology education, for both residents and medical students. Of the 12 studies included within this review, nine reported either improved objective performance in academic or clinical measures, or no difference in performance but higher satisfaction with use of e-learning materials, when compared to standard teaching methods ${ }^{(30)}$.

\section{Confounders of ENT training}

A career in surgery has been historically a competitive but attainable achievement for the highly committed and driven individual. In many countries however, we see a gradual deterioration of medical students interested in surgery ${ }^{(33-37)}$. The ENT specialty in the UK is not an exception, and the decrease in numbers has been a major cause for concern, falling from 184 applicants in 2013 to just 98 in $2016^{(36)}$.

There have been a number of studies looking at junior doctor attitudes to careers in surgery; most studies point to controllable lifestyle issues being of paramount importance in the decision of young medical graduates to avoid general surgery $(35,36,39-43)$. Factors such as prestige and professional satisfaction are overridden by issues including the length of training, number and difficulty of calls, and expected control over work hours, both during and after completion of residency. Other factors that were identified include financial indebtedness, appropriate personality traits, identification with a surgical mentor, intellectual challenge, clerkship experience, and patients' attitude ${ }^{(33-37)}$.

However, this attitude seems to change during the training Once in training positions, surgeons report lower levels of satisfaction than any of their junior doctor counterparts ${ }^{(42)}$. Interestingly, however, when results for job satisfaction are broken down by grade, it becomes apparent that senior trainees report being more content than early-years doctors. Equally, a study of US surgeons found that senior faculty were more satisfied and less burnt-out than their residents ${ }^{\left({ }^{43}\right)}$. A recent study by Walker et al. confirmed these results to be similar in the population of ENT surgeons ${ }^{(44)}$.

This suggests that reasons behind the dissatisfaction should be sought mainly at the junior level when choosing the specialty. A potential explanation may be reduced clinical experience and elective theatre exposure, which has been attributed to the European Working Time Directive (EWTD) amongst junior surgical trainees ${ }^{(47,48)}$. With this decreased exposure amongst surgical trainees, more junior doctors are also unlikely to gain supervised surgical experience, and are therefore restricted to ward-based work, which may be a detrimental influence in choosing surgery as a future career option.

We would encourage all surgical specialities to be pro-active in their recruitment. Not only at the medical school/core training level, but also at the higher surgical training level, as for the above-mentioned reasons we predict that this trend is likely to continue - if not worsen - before it gets any better.

\section{Surgical aspects of training}

\section{Cadaveric dissection}

Cadaveric dissection has been the cornerstone of gross anatomy teaching for centuries and constitutes a fundamental component of surgical education. There is no doubt that it significantly contributes to the understanding of the $3 \mathrm{D}$ disposition and relationship of all anatomical structures ${ }^{(2,47)}$. Unfortunately, there has been a reduction in the number of hours assigned to dissection in the anatomy curriculum during recent years. The reasons for this reduction are multiple; a reduction in availability of cadavers, increased costs of running dissection laboratories, and a change in emphasis, in favour of skills such as communication and teamwork among medical students ${ }^{(48)}$. 
For surgeons, in general, a profound knowledge of the anatomy is essential. For ENT trainees and fellows in specific, a thorough understanding of the difficult anatomy of the skull base, sinonasal cavities, inner, middle and external ear, oropharynx, larynx and neck are crucial. To conquer all this anatomical knowledge, cadaveric dissection provides a true feeling of identification of anatomical structures, provides detailed insights/information on anatomical variations, allows students to experience tissue handling, and makes students experience the operating theatre (OT) setting ${ }^{(49)}$. This latter observation is of utmost importance, as dissection allows the trainee to behave exactly the same as in the OT; the possibility to practice different approaches to the same area and different techniques to solve a problem will improve the self-confidence of the trainee.

A novelty in this field is sheep models. Even though the animals are alive throughout the surgery and therefore, strictly speaking, should not fall into this category, we included them as they afford a high-fidelity experience, while mimicking the haemodynamic changes one would expect in a situation of major haemorrhage, and incorporating the animal's innate haemostatic mechanisms to increase the reality of the situation ${ }^{(52,53)}$. The results of the latest study by Jukes et al. suggest that participants find the course realistic, that it is able to induce a stressful response, and that it provides participants with an increased level of confidence in their ability to deal with major vessel bleeding in an endoscopic environment ${ }^{(52)}$.

Courses organised with cadaveric dissection are a wonderful opportunity to learn from experienced surgeons in each field (55). It should be recommended to attend at least one otology, rhinology and neck dissection course by the end of ENT training. In the case of fellows, a more specialised training should be achieved, and ideally all the centres with fellows should have a dissection laboratory for the purposes of training and research/ dissection projects.

\section{Navigation and augmented reality}

The rhinologist in the operating room is limited by transformation of information from the three-dimensional (3-D) surgical field to two-dimensional (2-D) sections on the navigation screen. The surgeon is therefore confronted with the mental task of integrating these two image datasets. Surgical navigation (also known as image-guided surgery, or IGS) and augmented reality (AR) might be a way to overcome this problem. IGS provides a way for surgeons to track, during surgery, their instruments' tips relative to the preoperative imaging data ${ }^{(54)}$ (sinus CT scan for example). Recently, IGS systems are being combined with $A R$, which fuses computer-generated images of preoperative imaging data with real-time views of the surgical field ${ }^{(57,58)}$. This means that if the pathway to the frontal sinus is annotated on the preoperative $\mathrm{CT}$ images, the surgeon will visualize that pathway as a projection displayed over the live endoscopic images. IGS with AR may also function as a "target avoidance" mechanism by marking the dangerous structures so that their location is clear, before they are exposed during surgery. Examples of these IGS with AR commercially available are from Scopis (Scopis-TGS) and Storz (Storz NAV1), with the planning software of the former being based on the building-blocks concept proposed by Wormald ${ }^{(57)}$.

Evidence of IGS benefits in endoscopic sinus surgery (ESS) is conflicting. A systematic review by Dalgorf et al. concluded that there is evidence from published studies that the use of IGS for ESS is associated with a lower risk of major and total complications compared with non-IGS sinus surgery ${ }^{(60)}$. However, Ramakrishnan et al. in his review emphasised that the current evidence is limited and based on research with suboptimal methodology, therefore, the use of IGS in ESS is an option and should be based on clinical judgment and applied on a case-bycase basis ${ }^{(59)}$.

IGS with AR may facilitate the process of learning to read preoperative $\mathrm{CT}$ images, and applying that information during surgery, compared with traditional DICOM viewing software that presents CT images in the 3 orthogonal planes ${ }^{(55)}$. Even so, care should be taken since trainee sinus surgeons seeing their more experienced colleagues using a navigation device tend to overestimate the capabilities of the system and to underestimate the risks ${ }^{\left({ }^{62}\right)}$. The additional visual information provided by AR may shift users' attention to other targets, causing inattentional blindness of other important findings ${ }^{(61)}$.

IGS with or without AR should have a place in training and teaching of EES ${ }^{(62)}$, however clear recommendations need to be published concerning its use: is IGS mandatory as part of sinus surgeons' training? Should every department performing sinus/ skull base surgery have an IGS system?

\section{Virtual reality}

Simulation and virtual reality (VR) has become an essential part of training in medicine over the last 40 years ${ }^{(64-66)}$. ENT has been a very active field where these advancing technologies were implemented. In particular, tools for temporal bone surgery have been described in over 200 studies, as this anatomical location shows great complexity and variability ${ }^{(65-67)}$.

In rhinology, VR training for functional endoscopic sinus surgery might be appropriate ${ }^{(66)}$. In 1997, Wiet et al. reported about their collaboration in developing a virtual reality system that provides interaction with volume data, by employing real-time volume rendering and haptic feedback ${ }^{(67)}$. Ecke et al. ${ }^{(68)}$ and Rudman et 
al. ${ }^{(69)}$ published the first studies about VR simulators of endoscopic sinus surgery. In their nasal endoscopy simulator (NES), Ecke et al. used a computer-generated 3D model of patients' anatomy from CT or MR scans. The interaction between the anatomical simulations and applied instruments was archived through electromagnetic tracking systems. However, tactile feedback could not be achieved and acoustic signals were used when critical structures were injured ${ }^{(68)}$. Rudman et al. used cryosections to reconstruct the anatomy for their model. In a head model, electromagnetic forces were used to give haptic feedback to the user, who was asked to navigate the endoscope through the nasal cavity, as well as to perform surgical procedures like ethmoidectomy ${ }^{(69)}$.

Another application of implement VR in rhinologic training is the establishment of a web-based resource. This would especially help residents in countries where specialists are rare ${ }^{(70)}$. From all available simulators in the early 2000s, the Lockheed Martin endoscopic sinus surgery simulator (ES3) became the most studied. The ES3 runs on a Silicon Graphics workstation, a personal computer-based haptic controller, and an electromechanical haptic interface, with a model of an endoscope, a handle for surgical tools, and a head model. The system provides haptic feedback, reproducing resistance and vibration on the surgical instrument's handle. The ES3 can simulate bleeding, and image deterioration simulating a dirty lens. The simulator provides different instruments for each dissection step to reproduce a standard endoscopic sinus surgery procedure ${ }^{(71)}$.

To validate reliability of simulators, Arora et al. studied fundamental perceptual, visuospatial, and psychomotor abilities in a group of students and otolaryngology residents $(n=38)$ using ES3, a minimally invasive surgical trainer virtual reality (MISTVR), a pictorial surface orientation (PicSOr), and 3 visuospatial tests (cube comparison, card rotation, and map planning). The scores of ES3 correlated well with previously validated measures. Hence, the ES3 was shown as reliable tool in rhinology training ${ }^{(74)}$. Solyar et al. tested 8 probands with the ES3 against 7 probands learning from textbooks, where they had to identify anatomical structures after training with either medium. The ES3 group achieved higher scores in less time ${ }^{(73)}$. Fried et al. then translated ES3 training to the operating theatre, comparing a group of simulator-trained residents to residents who only had access to "conventional" learning material, where the latter was not specified. The first live surgery was recorded and evalu- ated by blinded expert surgeons. The results showed better outcomes for the ES3 group as regards time to completion of task (minutes), case difficulty, tool manipulation, tissue respect, task completion rate, surgical confidence (10-point scale) and number of errors. Errors were defined as dirty scope, wandering scope, failed attempt in orientation, lack of perspective in instrument view, collision, improper injection (of local anaesthesia), mucosal injury and bloody field ${ }^{(76)}$.

The most recently-introduced VR simulator for FESS was the McGill simulator in 2014. Additional tools applied include sinus washing and the simulated use of microdebriders. Moreover, the system can calculate the amount of tissues/structures removed by the microdebrider ${ }^{(75)}$. Despite promising results of previous studies for applicability and validity, Dharmawadana et al. validated four different simulators for four different groups from students to registrars. They concluded that VR simulators are helpful for the initial steps of surgical training, but would not be ready for more advanced skills as required by registrars ${ }^{(78)}$.

\section{Conclusions}

In conclusion, Piromchai et al. stated in their meta-analysis that overall, the evidence for VR simulators (temporal bone as well as sinonasal) indicates that they could be implemented as an adjunct in training programs, but cannot replace conventional methods. This is mainly due to the fact that actual surgical outcomes after VR training have not been studied so far, but may be the content of future larger scale studies ${ }^{(64)}$. Moreover, a survey among participants of ESS courses showed that tasks related to spatial orientation are judged as the hardest, whereas manual tasks are considered less difficult. This suggests that simulators will not necessarily require haptic feedback in order to train the most important knowledge and skills needed for FESS ${ }^{(77)}$. The more affordable alternatives might be anatomical models, which nowadays can be created using 3D printing technologies ${ }^{(80-82)}$.

\section{Authorship contribution}

PS: Introduction, Compiling the paragraphs, corrections, overview; TJ: Differences in training in Europe; AGM: Multidisciplinary approach to composition of training curriculum; a missing link; $A B, P S$ : The role of e-learning in residency training; PMD: Confounders of ENT training; CL: Cadaveric dissection; JP: Navigation and augmented reality; PVT: Virtual reality.

\section{Conflict of interest}

The authors do not have a conflict of interest.

\section{References}

1. Mace AD, Narula AA. Survey of current undergraduate otolaryngology training in the United Kingdom. J Laryngol Otol. 2004;118(3):217-20
2. Fokkens WJ. The endoscope: new opportunities requiring new skills. Rhinology. 2009;47(4):337-8.

3. Ryan MW, Johnson F. Fellowship training in otolaryngology-head and neck surgery.
Otolaryngologic clinics of North America. 2007;40(6):1311-22, viii-ix.

4. Luxenberger W, Ward VM, Nikolaou A, Neudert M, Bien S, Eichhorn T, et al. The development and design of the 
European Board of OtorhinolaryngologyHead and Neck Surgery Examination (EBEORL-HNS). Eur Arch Otorhinolaryngol. 2016;273(5):1079-93.

5. Oker $\mathrm{N}$, Alotaibi NH, Reichelt AC, Herman $\mathrm{P}$, Bernal-Sprekelsen M, Albers AE. European otorhinolaryngology training programs: results of a European survey about training satisfaction, work environment and conditions in six countries. Eur Arch Otorhinolaryngol. 2017;274(11):4017-29.

6. Oker N, Escabasse V, Al-Otaibi N, Coste A, Albers AE. Acquisition of diagnostic and surgical skills in otorhinolaryngology: a comparison of France and Germany. Eur Arch Otorhinolaryngol.. 2015;272(11):3565-73.

7. Shonka DC, Jr., Ghanem TA, Hubbard MA, Barker DA, Kesser BW. Four years of accreditation council of graduate medical education duty hour regulations: have they made a difference? Laryngoscope. 2009;119(4):635-9.

8. Pothier DD, Toll EC, Grant DG, Giddings CE. Trends in operative training opportunities for junior and senior trainees in otolaryngology. Clin Otolaryngol. 2009;34(2):179-84

9. Ooi EH, Witterick IJ. Rhinologic surgical training. Otolaryngologic clinics of North America. 2010;43(3):673-89, xi.

10. Dedmon MM, Locketz GD, Chambers KJ, Naunheim MR, Lin DT, Gray ST. Skull Base Surgery Training and Practice Patterns among Recent Otolaryngology Fellowship Graduates. J Neurol Surg B Skull Base. 2016;77(4):297-303.

11. Brozek JL, Bousquet J, Agache I, Agarwal A Bachert C, Bosnic-Anticevich S, et al. Allergic Rhinitis and its Impact on Asthma (ARIA) guidelines-2016 revision. J Allergy Clin Immunol. 2017;140(4):950-8.

12. Fokkens WJ, Lund VJ, Mullol J, Bachert C, Alobid I, Baroody F, et al. European Position Paper on Rhinosinusitis and Nasal Polyps 2012. Rhinology Supplement. 2012(23):3 p preceding table of contents, 1-298.

13. Hellings PW, Akdis CA, Bachert $C$, Bousquet J, Pugin B, Adriaensen G, et al. EUFOREA Rhinology Research Forum 2016: report of the brainstorming sessions on needs and priorities in rhinitis and rhinosinusitis, Rhinology. 2017:55(3):202-10.

14. Cornelis M, Rombaux $P$, Jorissen $M$, Hellings PW. Nationwide survey on immunotherapy practice by ENT specialists. Rhinology. 2014;52(1):72-7.

15. Varendh M, Johannisson A, Hrubos-Strom $H$, Andersson M. Sleep quality improves with endoscopic sinus surgery in patients with chronic rhinosinusitis and nasal polyposis. Rhinology. 2017;55(1):45-52

16. Jiang RS, Liang KL, Hsin CH, Su MC. The impact of chronic rhinosinusitis on sleep-disordered breathing. Rhinology. 2016;54(1):75-9

17. Blomster $H$, Kemppainen $T$, Numminen J, Ruoppi P, Sahlman J, Peltonen M, et al. Impaired nasal breathing may prevent the beneficial effect of weight loss in the treatment of OSA. Rhinology. 2011;49(5):587-92.
18. Kotecha B. The nose, snoring and obstructive sleep apnoea. Rhinology. 2011;49(3):259-63.

19. Rombaux P, Liistro G, Hamoir M, Bertrand B, Aubert $G$, Verses $T$, et al. Nasal obstruction and its impact on sleep-related breathing disorders. Rhinology. 2005;43(4):242-50.

20. Kenn K, Balkissoon R. Vocal cord dysfunction: what do we know? Eur Respir J. 2011;37(1):194-200.

21. Balatsouras DG, Kaberos AC, Korres SG, Economou NC, Assimakopoulos D. Rhinology resources on the internet: a critical review. Rhinology. 2004;42(3):158-63.

22. Balatsouras DG, Kaberos A, Kantas I, Mourtzouhos C, Korres SG, Kandiloros D. Rhinology resources on the internet: an update. Rhinology. 2009;47(1):93-101.

23. Balatsouras DG, Kaberos AC, Leontiadis A, Korres SG, Ferekidis E, Economou C. Rhinology resources on the Internet. Rhinology. 2002;40(4):229-34.

24. Jayakumar N, Brunckhorst O, Dasgupta P, Khan MS, Ahmed K. e-Learning in Surgical Education: A Systematic Review. J Surg Educ. 2015;72(6):1145-57.

25. Glicksman JT, Brandt MG, Moukarbel RV, Rotenberg B, Fung K. Computerassisted teaching of epistaxis management: a Randomized Controlled Trial. Laryngoscope. 2009;1 19(3):466-72

26. Mendez A, Seikaly H, Ansari K, Murphy R, Cote D. High definition video teaching module for learning neck dissection. J Otolaryngol Head Neck Surg. 2014;43:7.

27. Beyea JA, Wong E, Bromwich M, Weston WW, Fung K. Evaluation of a particle repositioning maneuver Web-based teaching module. Laryngoscope. 2008;118(1):175-80.

28. Subramanian A, Timberlake M, Mittakanti $\mathrm{H}$, Lara M, Brandt ML. Novel educational approach for medical students: improved retention rates using interactive medical software compared with traditional lecturebased format. J Surg Educ. 2012;69(4):44952.

29. Hughes JP, Quraishi MS. YouTube resources for the otolaryngology trainee. J Laryngol Otol. 2012;126(1):61-2.

30. Wong MC, Fung K. Mobile applications in otolaryngology-head and neck surgery. Otolaryngol Head Neck Surg. 2015;152(4):638-43.

31. Feng JY, Chang YT, Chang HY, Erdley WS, Lin $\mathrm{CH}$, Chang YJ. Systematic review of effectiveness of situated e-learning on medical and nursing education. Worldviews Evid Based Nurs. 2013;10(3):174-83.

32. Tarpada SP, Hsueh WD, Gibber MJ. Resident and student education in otolaryngology: A 10-year update on e-learning. Laryngoscope. 2017;127(7):E219-E24.

33. Ko CY, Escarce JJ, Baker L, Klein D, Guarino C. Predictors for medical students entering a general surgery residency: National survey results. Surgery. 2004;136(3):567-72.

34. Are C, Stoddard HA, Huggett K, Franzen J, Mack A, Thompson JS. A regional perspective on the attitudes of fourth-year medical students toward the field of general surgery. J Surg Educ. 2009;66(3):123-8.

35. McCord JH, McDonald R, Sippel RS, Leverson G, Mahvi DM, Weber SM. Surgical career choices: the vital impact of mentoring. J Surg Res. 2009;155(1):136-41.

36. Tambyraja AL, McCrea CA, Parks RW, Garden OJ. Attitudes of medical students toward careers in general surgery. World J Surg. 2008:32(6):960-3.

37. Zarebczan B, McDonald RJ, Foley E, Weber SM. The dying field of general surgery: when do we intervene? J Surg Res. 2010;160(1):25-8.

38. Richard G, Richard S, Kerry H. Declining applications to surgical specialist training. The Bulletin of the Royal College of Surgeons of England. 2017;99(4):142-4.

39. Sanfey HA, Saalwachter-Schulman AR, Nyhof-Young JM, Eidelson B, Mann BD. Influences on medical student career choice: gender or generation? Arch Surg. 2006;141(11):1086-94; discussion 94.

40. Gelfand DV, Podnos YD, Wilson SE, Cooke J, Williams RA. Choosing general surgery: insights into career choices of current medical students. Arch Surg 2002;137(8):941-5; discussion 5-7.

41. Cochran A, Melby S, Neumayer LA. An Internet-based survey of factors influencing medical student selection of a general surgery career. Am J Surg. 2005;189(6):742-6.

42. Fischer JE. The impending disappearance of the general surgeon. Jama. 2007:298(18):2191-3.

43. Stockinger $Z T$, Ellis $M S, M c S w a i n ~ N E, ~ J r$. Residents and medical students in the 21st century: better, worse, or just different? Bulletin of the American College of Surgeons. 2004;89(11):21-3.

44. Council GM. National training survey 2014. 2014.

45. Golub JS, Weiss PS, Ramesh AK, Ossoff RH, Johns MM, 3rd. Burnout in residents of otolaryngology-head and neck surgery: a national inquiry into the health of residency training. Acad Med. 2007;82(6):596-601.

46. Walker A, Hines J, Brecknell J. Survival of the Grittiest? Consultant Surgeons Are Significantly Grittier Than Their Junior Trainees. J Surg Educ. 2016;73(4):730-4.

47. Patel RK, Sayers AE, Akbar MJ, Hunter IA. A survey to determine the potential impact of foundation year career aims on surgical specialty training. Ann Med Surg (Lond). 2014;3(1):13-7.

48. Morris-Stiff GJ, Sarasin S, Edwards P, Lewis WG, Lewis MH. The European Working Time Directive: One for all and all for one? Surgery. 2005;137(3):293-7.

49. Van Wyk J, Rennie C, VAN WYK J, CO R. Learning anatomy through dissection: Perceptions of a diverse medical student cohort. Int j morphol. 2015;33(1):89-95.

50. Ahmed K, Rowland S, Patel VM, Ashrafian H, Davies DC, Darzi A, et al. Specialist anatomy: Is the structure of teaching adequate? Surgeon. 2011;9(6):312-7.

51. McBride JM, Drake RL. Use of Unembalmed/ 
Fresh Cadavers in Anatomy Teaching. In: Chan LK, Pawlina W, editors. Teaching Anatomy: A Practical Guide. Cham: Springer International Publishing; 2015. p. 223-6.

52. Valentine R, Wormald PJ. A Vascular Catastrophe during Endonasal Surgery: An Endoscopic Sheep Model. Skull Base. 2011;21(2):109-14.

53. Valentine R, Wormald PJ. Controlling the surgical field during a large endoscopic vascular injury. Laryngoscope. 2011;121(3):5626.

54. Jukes AK, Mascarenhas A, Murphy J, Stepan L, Munoz TN, Callejas CA, et al. Stress response and communication in surgeons undergoing training in endoscopic management of major vessel hemorrhage: a mixed methods study. Int Forum Allergy Rhinol. 2017;7(6):576-83.

55. Braun T, Betz CS, Ledderose GJ, Havel M, Stelter K, Kuhnel T, et al. Endoscopic sinus surgery training courses: benefit and problems - a multicentre evaluation to systematically improve surgical training. Rhinology. 2012;50(3):246-54.

56. Citardi MJ, Yao W, Luong A. Next-Generation Surgical Navigation Systems in Sinus and Skull Base Surgery.Otolaryngol Clin North Am. 2017;50(3):617-32

57. Citardi MJ, Agbetoba A, Bigcas JL, Luong A. Augmented Reality for Endoscopic Sinus Surgery With Surgical Navigation: A Cadaver Study. Int Forum Allergy Rhinol. 2016;6(5):523-8.

58. Caversaccio M, Garcia Giraldez J, Thoranaghatte R, Zheng G, Eggli P, Nolte $L P$, et al. Augmented reality endoscopic system (ARES): preliminary results. Rhinology. 2008;46(2):156-8.

59. Wormald P-J. Three-dimensional building block approach to understanding the anatomy of the frontal recess and frontal sinus. Operative Techniques in OtolaryngologyHead and Neck Surgery. 2006;17(1):2-5.

60. Dalgorf DM, Sacks R, Wormald PJ, Naidoo Y, Panizza B, Uren B, et al. Image-guided surgery influences perioperative morbidity from endoscopic sinus surgery: a systematic review and meta-analysis. Otolaryngol Head Neck Surg. 2013;149(1):17-29.

61. American Academy of OtolaryngologyHead and Neck Surgery. Intra-operative use of computer aided surgery. 2012. Available from: http://www.entnet.org/Practice/policylntraOperativeSurgery.cfm.

62. Stelter K, Ertl-Wagner B, Luz M, Muller S, Ledderose G, Siedek V, et al. Evaluation of an image-guided navigation system in the training of functional endoscopic sinus surgeons. A prospective, randomised clinical study. Rhinology. 2011;49(4):429-37.

63. Dixon BJ, Daly MJ, Chan HH, Vescan A Witterick IJ, Irish JC. Inattentional blindness increased with augmented reality surgical navigation. Am J Rhinol Allergy. 2014;28(5):433-7.

64. Javia L, Deutsch ES. A systematic review of simulators in otolaryngology. Otolaryngol Head Neck Surg. 2012;147(6):999-1011.

65. Arora A, Lau LY, Awad Z, Darzi A, Singh A Tolley N. Virtual reality simulation training in Otolaryngology. Int J Surg. 2014;12(2):87-94

66. Piromchai $P$, Avery A, Laopaiboon M Kennedy G, O'Leary S. Virtual reality training for improving the skills needed for performing surgery of the ear, nose or throat. Cochrane Database Syst Rev. 2015(9):Cd010198.

67. Lui JT, Hoy MY. Evaluating the Effect of Virtual Reality Temporal Bone Simulation on Mastoidectomy Performance: A Metaanalysis. Otolaryngol Head Neck Surg. 2017;156(6):1018-24.

68. Baudoin T, Grgic MV, Zadravec D, Geber G, Tomljenovic D, Kalogjera L. Algorithm for navigated ESS. Rhinology. 2013;51(4):33542.

69. Wiet GJ, Yagel R, Stredney D, Schmalbrock P, Sessanna DJ, Kurzion Y, et al. A volumetric approach to virtual simulation of functional endoscopic sinus surgery. Stud Health Technol Inform. 1997;39:167-79.

70. Ecke U, Klimek L, Muller W, Ziegler R, Mann W. Virtual reality: preparation and execution of sinus surgery. Comput Aided Surg. 1998;3(1):45-50.

71. Rudman DT, Stredney D, Sessanna D, Yagel R, Crawfis R, Heskamp D, et al. Functional endoscopic sinus surgery training simulator. Laryngoscope. 1998;108(11 Pt 1):1643-7.

72. Navarro Newball AA, Hernandez CJ, Velez JA, Munera LE, Garcia GB, Gamboa CA, et al. Virtual surgical telesimulations in otolaryngology. Stud Health Technol Inform. 2005;111:353-5.

73. Fried MP, Uribe JI, Sadoughi B. The role of virtual reality in surgical training in otorhinolaryngology. Otolaryngol Head Neck Surg. 2007;15(3):163-9.

74. Arora H, Uribe J, Ralph W, Zeltsan M, Cuellar H, Gallagher A, et al. Assessment of construct validity of the endoscopic sinus surgery simulator. Arch Otolaryngol Head Neck Surg. 2005;131(3):217-21.

75. Solyar A, Cuellar H, Sadoughi B, Olson TR, Fried MP. Endoscopic Sinus Surgery
Simulator as a teaching tool for anatomy education. Am J Surg. 2008;196(1):120-4.

76. Fried MP, Sadoughi B, Gibber MJ, Jacobs $J B$, Lebowitz RA, Ross DA, et al. From virtual reality to the operating room: the endoscopic sinus surgery simulator experiment. Otolaryngol Head Neck Surg. 2010;142(2):202-7.

77. Varshney R, Frenkiel S, Nguyen LH, Young M, Del Maestro R, Zeitouni A, et al. Development of the McGill simulator for endoscopic sinus surgery: a new highfidelity virtual reality simulator for endoscopic sinus surgery. Am J Rhinol Allergy. 2014;28(4):330-4.

78. Dharmawardana N, Ruthenbeck G, Woods C, Elmiyeh B, Diment $L$, Ooi EH, et al. Validation of virtual-reality-based simulations for endoscopic sinus surgery. Clin Otolaryngol. 2015;40(6):569-79.

79. Bakker NH, Fokkens WJ, Grimbergen CA. Investigation of training needs for functional endoscopic sinus surgery (FESS). Rhinology. 2005;43(2):104-8.

80. Briner HR, Simmen $D$, Jones $N$, Manestar $D$, Manestar M, Lang A, et al. Evaluation of an anatomic model of the paranasal sinuses for endonasal surgical training. Rhinology. 2007:45(1):20-3.

81. AlReefi MA, Nguyen LH, Mongeau LG, Haq BU, Boyanapalli S, Hafeez N, et al. Development and validation of a septoplasty training model using 3-dimensional printing technology. Int Forum Allergy Rhinol. 2017:7(4):399-404

82. Chang DR, Lin RP, Bowe S, Bunegin L, Weitzel EK, McMains KC, et al. Fabrication and validation of a low-cost, mediumfidelity silicone injection molded endoscopic sinus surgery simulation model. Laryngoscope. 2017;127(4):781-6.

\section{Dr. Pavol Šurda}

Guy's and St Thomas' University

Hospital

Great Maze Pond

SE1 7EH, London

United Kingdom

Tel: +44-53-999 8211

E-mail:pavol.surda@gmail.com 